\title{
SERIAL BLOOD LACTATE MEASUREMENTS PREDICT EARLY OUTCOME AFTER NEONATAL REPAIR OR PALLIATION FOR COMPLEX CONGENITAL HEART DISEASE
}

John R. Charpie, MD, PhD

Mary K. Dekeon, RRT

Caren S. Goldberg, MD, MPH

Ralph S. Mosca, MD

Edward L. Bove, MD

Thomas J. Kulik, MD
Objectives: Neonates with congenital heart disease may appear hemodynamically stable after operation and then suddenly experience catastrophic decompensation. An improved means of predicting which infants will suddenly die in the early postoperative period may lead to lifesaving interventions. Studies indicate that blood lactate level is proportional to tissue oxygen debt, but information linking lactate levels with outcome in infants after operation is limited. We sought to determine whether a change in lactate level over time was predictive of a poor outcome defined as death within the first 72 hours or the need for extracorporeal membrane oxygenation.

Methods: To test this hypothesis, we studied prospectively 46 infants who were less than 1 month old and were undergoing complex cardiac surgical palliation or repair. Postoperative arterial oxygen saturation, bicarbonate, and lactate levels were recorded on admission to the intensive care unit and every 3 to 12 hours for the first 3 days.

Results: Thirty-seven patients had a good outcome, and 9 patients had a poor outcome. Mean initial lactate level was significantly greater in patients with a poor outcome $(9.4 \pm 3.8 \mathrm{mmol} / \mathrm{L})$ than in patients with a good outcome $(5.6 \pm 2.1 \mathrm{mmol} / \mathrm{L} ; P=.03)$. However, an elevated initial lactate level of more than $6 \mathrm{mmol} / \mathrm{L}$ had a low positive predictive value $(38 \%)$ for poor outcome. In contrast, a change in lactate level of $0.75 \mathrm{mmol} / \mathrm{L}$ per hour or more was associated with a poor outcome $(P<.0001)$ and predicted a poor outcome with an $89 \%$ sensitivity value, a $100 \%$ specificity value, and a $100 \%$ positive predictive value.

Conclusions: Serial blood lactate level measurements may be an accurate predictor of death or the requirement for extracorporeal membrane oxygenator support for patients who undergo complex neonatal cardiac surgery. (J Thorac Cardiovasc Surg 2000;120:73-80)
$A^{\prime}$ important adjunct to the improvement of low cariac output in patients after operation for complex congenital heart disease would be the availability of an appropriate tool that can serve as a useful marker of

From the University of Michigan Congenital Heart Center, University of Michigan Medical Center, Ann Arbor, Mich.

Received for publication July 7, 1999; revisions requested Sept 15, 1999; revisions received Nov 12, 1999; accepted for publication Feb 28, 2000.

Address for reprints: John R. Charpie, MD, PhD, F1511 MCHC/Box 0204, University of Michigan, 1500 E. Medical Center Dr, Ann Arbor, MI 48109-0204 (E-mail: jcharpie@umich.edu).

Copyright () 2000 by The American Association for Thoracic Surgery

$0022-5223 / 2000 \$ 12.00+0 \quad \mathbf{1 2 / 1 / 1 0 6 8 3 8}$

doi:10.1067/mtc. 2000.106838 clinically relevant cellular hypoxia and tissue malperfusion before the development of catastrophic change in cardiovascular status. This information is perhaps even more critical for neonates who undergo palliation for univentricular hearts and who are particularly prone to pulmonary overcirculation, coronary ischemia, and low cardiac output as the result of shunt-dependent pulmonary blood flow. Ideally, this clinical tool would not only signal impending circulatory failure but, with appropriate treatment, might help to monitor the response to therapy.

Recent studies in experimental animals and critically ill adult patients have shown that the degree of increase in blood lactate level is proportional to the severity of tissue oxygen deficiency and the decrease in oxygen delivery. ${ }^{1,2}$ During anaerobic conditions, pyruvate (the 
Table I. Diagnosis and procedure

\begin{tabular}{lcl}
\hline \multicolumn{1}{c}{ Diagnosis } & No. of patients & \multicolumn{1}{c}{ Procedure } \\
\hline Group I (Norwood) & & \\
HLHS & 26 & $\begin{array}{l}\text { Modified Norwood } \\
\text { Modified Norwood } \\
\text { Unbalanced AVSD, HLV }\end{array}$ \\
DILV, HRV, SAS, HAA/IAA & 2 & Modified Norwood \\
IAA, VSD, AS & 1 & Modified Norwood \\
Group II (non-Norwood) & 1 & Pulmonary vein repair, pulmonary valvotomy, PDA ligation \\
Heterotaxy syndrome, unbalanced AVSD, HLV, TAPVR & 1 & Rastelli procedure, aortic arch repair \\
IAA, VSD, SAS & 1 & Ross procedure, aortic arch repair, VSD closure \\
CoA, VSD, AS & 1 & Aortic arch repair, VSD closure \\
CoA, multiple VSD & 2 & ASO \\
D-TGA & 1 & ASO, VSD closure, aortic arch repair \\
D-TGA, multiple VSDs, CoA & 1 & ASO, VSD closure, aortic arch repair \\
DORV, D-MGA, CoA & 1 & Atrial septectomy, PAB \\
TA, D-MGA, HRV & 1 & BTS, pulmonary artery augmentation \\
L-TGA, PA, common AVV, TAPVR & 2 & Right ventricle-pulmonary artery conduit \\
TOF, APV & &
\end{tabular}

$H L H S$, Hypoplastic left heart syndrome; $A V S D$, atrioventricular septal defect; $H L V$, hypoplastic left ventricle; $D I L V$, double-inlet left ventricle; $H R V$, hypoplastic right ventricle; $S A S$, subaortic stenosis; $H A A$, hypoplastic aortic arch; $I A A$, interrupted aortic arch; VSD, ventricular septal defect; $A S$, aortic valve stenosis; TAPVR, total anomalous pulmonary venous return; $C O A$, aortic coarctation; $D-T G A$, dextro-transposition of the great arteries; $P D A$, patent ductus arteriosus; $A S O$, arterial switch operation; $D O R V$, double-outlet right ventricle; $D-M G A$, dextro-malposition of the great arteries; $T A$, tricuspid atresia; $P A B$, pulmonary artery banding; $L-T G A$, levotransposition of the great arteries; $P A$, pulmonary atresia; $A V V$, atrioventricular valve; $B T S$, Blalock-Taussig shunt; $T O F$, tetralogy of Fallot; $A P V$, absent pulmonary valve.

end product of glycolysis) is converted to lactate by the transfer of 2 hydrogen atoms from the coenzyme nicotinamide adenine dinucleotide. Blood lactate concentrations in critically ill and injured adult patients can be used to detect tissue hypoxia at an early stage, assess illness severity, and predict outcome. ${ }^{3-6}$ However, despite the volume of information on the value of blood lactate measurement in adult patients, information on its potential importance in critically ill neonates is limited. Hyperlactatemia has been reported to be an early indicator of sepsis ${ }^{7}$ and is associated with death in preterm infants with respiratory distress syndrome. . $^{89}$ Increased lactate concentrations have also been demonstrated in term infants with severe respiratory failure that requires extracorporeal membrane oxygenation (ECMO). ${ }^{10}$ Using a receiver operating characteristic analysis, Hatherhill and colleagues ${ }^{11}$ found that an initial lactate level of $6 \mathrm{mmol} / \mathrm{L}$ had the optimum predictive value for the death of children after cardiac operations. In a recent publication, Deshpande and Ward Platt $^{12}$ suggested that blood lactate concentrations might provide early warning signs and important prognostic information in ill neonates who were mechanically ventilated.

Therefore, the objective of this study was to determine whether serial blood lactate level measurements would prove valuable for the assessment of postoperative tissue perfusion and cardiac output for patients with complex congenital heart disease after neonatal surgical repair or palliation. Our focus on the first 72 hours after operation as a review of our own experience with Norwood palliation indicated that $56 \%$ of all patients who die outside the operating room and before hospital discharge, die within the first 72 postoperative hours.

\section{Patients and methods}

Patients. A prospective, observational study was performed on 42 consecutive neonates who required cardiopulmonary bypass for repair or palliation of complex congenital heart disease within the first month of life between August 1998 and April 1999 at C.S. Mott Children's Hospital, University of Michigan Medical Center. An additional 4 infants were included from a pilot study performed during the first 2 weeks of March 1998. Parental permission was obtained for inclusion in the study, and the research protocol was approved by The University of Michigan Medical School Institutional Review Board for Human Subject Research. The median age of operation was 6.0 days (range, 0-24 days), and the mean birth weight was $3.2 \pm 0.5 \mathrm{~kg}$ (range, $2.1-4.2 \mathrm{~kg}$ ). The precise anatomic diagnoses were generally outlined by transthoracic 2-dimensional echocardiography alone (Table I). Preoperative cardiac catheterization was reserved for those few patients whose condition required further anatomic details that were incompletely delineated by echocardiogram.

Postoperatively, all patients remained intubated and mechanically ventilated in volume control mode (Servo-300 or -900C ventilator; Siemens Medical Systems, Inc, Danvers, Mass) with a tidal volume of approximately $20 \mathrm{~mL} / \mathrm{kg}$, fractional inspired oxygen of $100 \%$, and a ventilator rate of 20 to 30 breaths/min. Patients with univentricular, shunt-dependent physiology were generally rapidly weaned as tolerated to room air (over several hours), in an attempt to minimize 
Table II. Diagnosis and outcome characteristic

\begin{tabular}{clcc}
\hline Patient No. & Diagnosis & $E C M O(E) /$ decreased $(D)$ & Time E/D $(h)$ \\
\hline Group I (Norwood) & & & 24.0 \\
1 & HLHS & $\mathrm{D}^{*}$ & 57.5 \\
2 & HLHS & $\mathrm{D}$ & 7.5 \\
3 & HLHS & $\mathrm{D}$ & 12.0 \\
4 & HLHS & $\mathrm{D}$ & 9.0 \\
5 & DILV, HRV, SAS, CoA & $\mathrm{E}$ & 9.0 \\
6 & HLHS & $\mathrm{E}$ & 6.0 \\
7 & HLHS & $\mathrm{E}$ & 4.0 \\
8 & HLHS & $\mathrm{E}$ & 44.0 \\
Group II (non-Norwood) & Heterotaxy syndrome, unbalanced & $\mathrm{D}^{*}$ & \\
9 & AVSD, HLV, TAPVR & & \\
\hline
\end{tabular}

$H L H S$, Hypoplastic left heart syndrome; $D I L V$, double-inlet left ventricle; $H R V$, hypoplastic right ventricle; SAS, subaortic stenosis; $C o A$, aortic coarctation; $A V S D$, atrioventricular septal defect; $H L V$, hypoplastic left ventricle; TAPVR, total anomalous pulmonary venous return.

*Patient removed from life-support.

excessive pulmonary blood flow. If possible, patients with two ventricles were weaned to less than $60 \%$ inspired oxygen.

Most of the patients returned from the operating room with an open sternotomy. Patients were initially sedated with fentanyl $(6 \mu \mathrm{g} / \mathrm{kg}$ per hour) for the first 24 to 48 hours followed by morphine sulfate infusion $(30 \mu \mathrm{g} / \mathrm{kg}$ per hour). Neuromuscular blockade (pancuronium $0.1 \mathrm{mg} / \mathrm{kg}$ dose every hour as needed) was used for the first postoperative day in patients whose condition was hemodynamically unstable. All patients returned from the operating room on continuous intravenous inotropic support with the use of one or more of dopamine, epinephrine, and milrinone. Support with an extracorporeal membrane oxygenator (ECMO) was initiated for 5 patients from 4 to 72 hours after operation. The indications for ECMO support were inadequate systemic perfusion, hypotension, and persistent metabolic acidosis.

Arterial oxygen saturation, bicarbonate, and blood lactate level measurements were recorded with a pediatric blood gas analyzer (Radiometer ABL 725; Radiometer A/S, Copenhagen, Denmark) on admission to the intensive care unit, every 3 to 6 hours for the first postoperative day, and every 6 to 12 hours for the subsequent 2 days. The Radiometer ABL 725 analyzer directly measures $\mathrm{pH}$ and lactate, $\mathrm{PCO}_{2}, \mathrm{PO}_{2}$, and hemoglobin levels and automatically calculates bicarbonate and oxygen saturation. The range of normal serum lactate levels is 0.5 to $2.2 \mathrm{mmol} / \mathrm{L}$. Cardiopulmonary bypass and circulatory arrest times were recorded for every patient.

Data analysis and statistics. A good outcome was defined as survival beyond postoperative day 3 , and a poor outcome was defined as death or the need for ECMO. Because the physiologic features of patients with a single ventricle who underwent Norwood palliation differ from those of patients after other neonatal operations, we analyzed the data in terms of all patients considered together and of those patients who underwent Norwood palliation (group I; $\mathrm{n}=34$ ) versus patients who underwent non-Norwood palliation (group II; n $=12$ ) separately. Preliminary inspection of our data from an earlier pilot study suggested that an increase in lactate level over time correlated with a poor outcome. With the use of a receiver operating characteristic analysis, a maximum increase in lactate level greater than $0.75 \mathrm{mmol} / \mathrm{L}$ per hour had the optimum predictive value for a poor outcome in children after heart surgery. A maximum change in lactate level (millimoles per liter) over time (1 hour) was therefore determined for each patient, and a new binomial variable (a change in lactate level of less than $<0.75$ or $\geq 0.75 \mathrm{mmol} / \mathrm{L}$ per hour) was created.

Data were collected and stored with the use of Microsoft Excel software (Microsoft Corporation; Redmond, Wash). Univariate analysis of lactate and bicarbonate measurements was performed at each time point. Differences in the continuous variables, and of other potential predictors, between good outcome and poor outcome subgroups were tested with the Student $t$ test. Differences between subgroups in categoric variables were tested with the $\chi^{2}$ test and the Fisher exact test. Contingency tables were formulated to determine the sensitivity value, specificity value, positive predictive value, and negative predictive value of both lactate level on admission of more than $6 \mathrm{mmol} / \mathrm{L}$ and a change in lactate level of 0.75 $\mathrm{mmol} / \mathrm{L}$ per hour or more. Multivariable logistic modeling that used the admission lactate level, change in lactate level per hour, cardiopulmonary bypass time, circulatory arrest time, and Norwood operation was performed for the outcome variable. Simple linear regression was used to test the relationship between the continuous variables of bicarbonate and lactate. Statistical analyses were performed with the use of Prism (GraphPad Software, Inc, San Diego, Calif) and SAS (SAS Institute, Inc, Cary, NC) software.

\section{Results}

All patients. Thirty-seven patients had a good outcome, 5 patients died, and 4 patients required ECMO. One of the 5 patients who died was an infant with aortic atresia, mitral stenosis, and a dilated poorly con- 


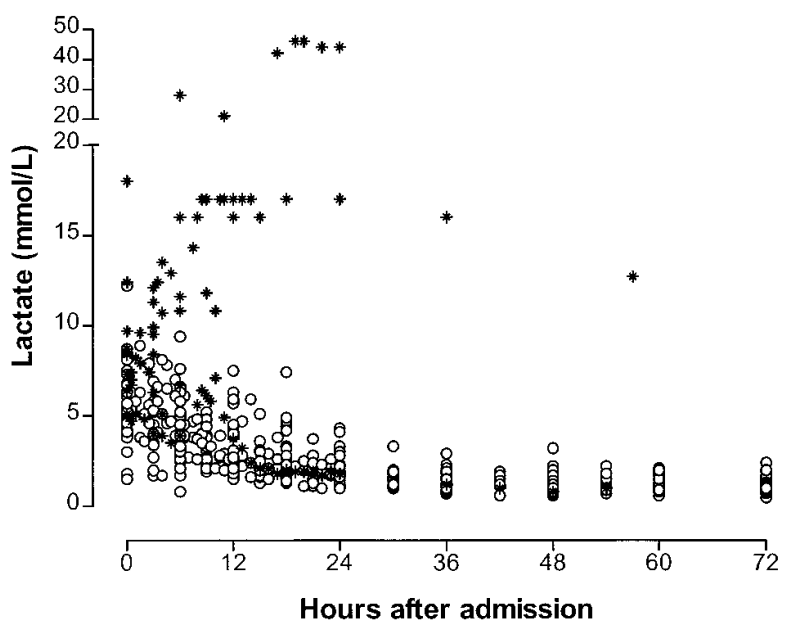

Fig 1. Individual arterial blood lactate concentrations for all patients during the first 72 hours after admission to the intensive care unit. $\bigcirc$, Patients with a good outcome; *, patients with a poor outcome.

tractile left ventricle with marked endocardial fibroelastosis (patient 1; Table II). This patient underwent a modified Norwood procedure in addition to a mitral valvectomy to decompress the left ventricle. After the operation, the patient had a severely low cardiac output with hypotension, poor systemic perfusion, persistent acidosis, and lactate levels between 12 and $44 \mathrm{mmol} / \mathrm{L}$ for the first 24 hours. Another of the 5 patients who died was an infant with intrauterine growth retardation (birth weight [at term], $2.1 \mathrm{~kg}$ ) and heterotaxy syndrome with complex congenital heart disease who underwent emergency surgery consisting of reanastomosis of the common pulmonary vein to the left atrium, pulmonary valvotomy, and ductus ligation (patient 9; Table II). He was returned to the intensive care unit with significant hypotension, persistent acidosis, low systemic perfusion, and lactate levels between 16 and $28 \mathrm{mmol} / \mathrm{L}$ for the initial 36 postoperative hours. By 44 hours and 24 hours, respectively, both of these patients were moribund and were therefore removed from lifesupport systems.

The mean initial lactate level was significantly greater in patients who died or who required ECMO support $(9.4 \pm 3.8 \mathrm{mmol} / \mathrm{L})$ than in patients with a good outcome $(5.6 \pm 2.1 \mathrm{mmol} / \mathrm{L} ; P=.03)$. However, an initial lactate level of more than $6 \mathrm{mmol} / \mathrm{L}$ had a low positive predictive value (38\%) for poor outcome (Figs 1 and 2). In contrast, an increasing lactate level over time (a change in lactate level of $0.75 \mathrm{mmol} / \mathrm{L}$ per hour or more) was associated with death or the requirement for ECMO support $(P<.0001)$ and predicted a poor out-

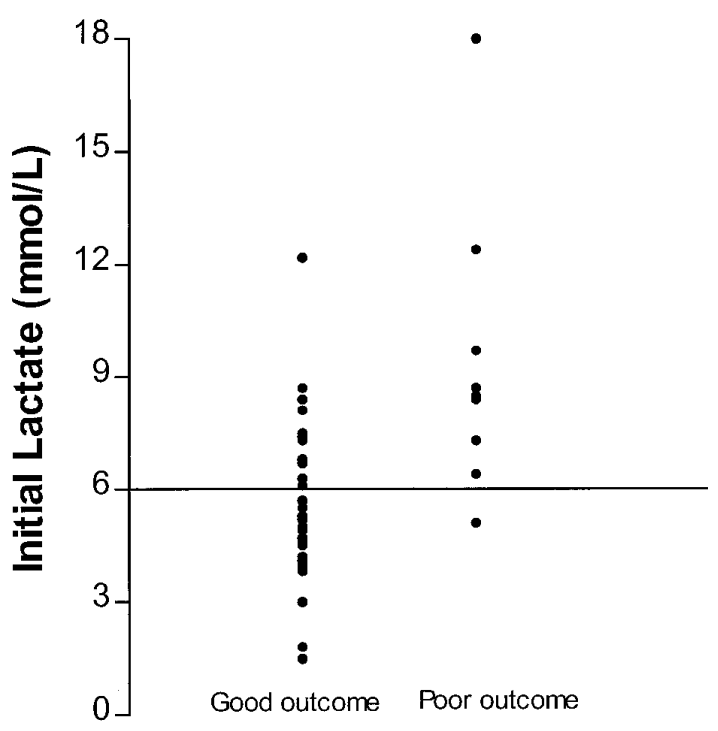

Fig 2. Initial arterial blood lactate concentrations for all patients on admission to the intensive care unit. Mean initial blood lactate level was greater in patients who died or who required ECMO support than in patients with a good outcome $(P=.03)$. However, an initial lactate level of more than 6 $\mathrm{mmol} / \mathrm{L}$ had a low positive predictive value $(38 \%)$ for poor outcome.

come with an $89 \%$ sensitivity value, a $100 \%$ specificity value, and a $100 \%$ positive predictive value. The negative predictive value for a poor outcome of a lactate level rise of less than $0.75 \mathrm{mmol} / \mathrm{L}$ per hour was 97\% $(P<.0001)$. This abrupt increase in lactate level preceded any emergency resuscitative efforts for infants who died or required ECMO. In addition, serial mean lactate levels decreased progressively in all patients with a good outcome and were within the normal range by 24 hours (Fig 1).

Although admission bicarbonate levels were significantly lower in patients with a poor outcome $(20 \pm 2.3$ $\mathrm{mmol} / \mathrm{L}$ ) compared with patients with a good outcome $(25 \pm 3.8 \mathrm{mmol} / \mathrm{L} ; P=.0003)$, by 18 hours the mean values were not significantly different $(24 \pm 2.8$ $\mathrm{mmol} / \mathrm{L}$ and $26 \pm 2.5 \mathrm{mmol} / \mathrm{L}$, respectively; Fig 3 ). We found minimal correlation between admission lactate levels and bicarbonate measures $\left(R^{2}=0.21 ; P=.002\right)$. Graphic analysis (Fig 4) confirmed a wide range of bicarbonate measurements for any lactate level.

For all patients, neither cardiopulmonary bypass time nor circulatory arrest time was substantially different between patients with a good outcome ( $87 \pm 40.2 \mathrm{~min}$ utes and $45.6 \pm 12.3$ minutes, respectively) and patients with a poor outcome $(84.9 \pm 20.3$ minutes and $44.2 \pm$ 8.2 minutes, respectively). Multivariate analysis (with 


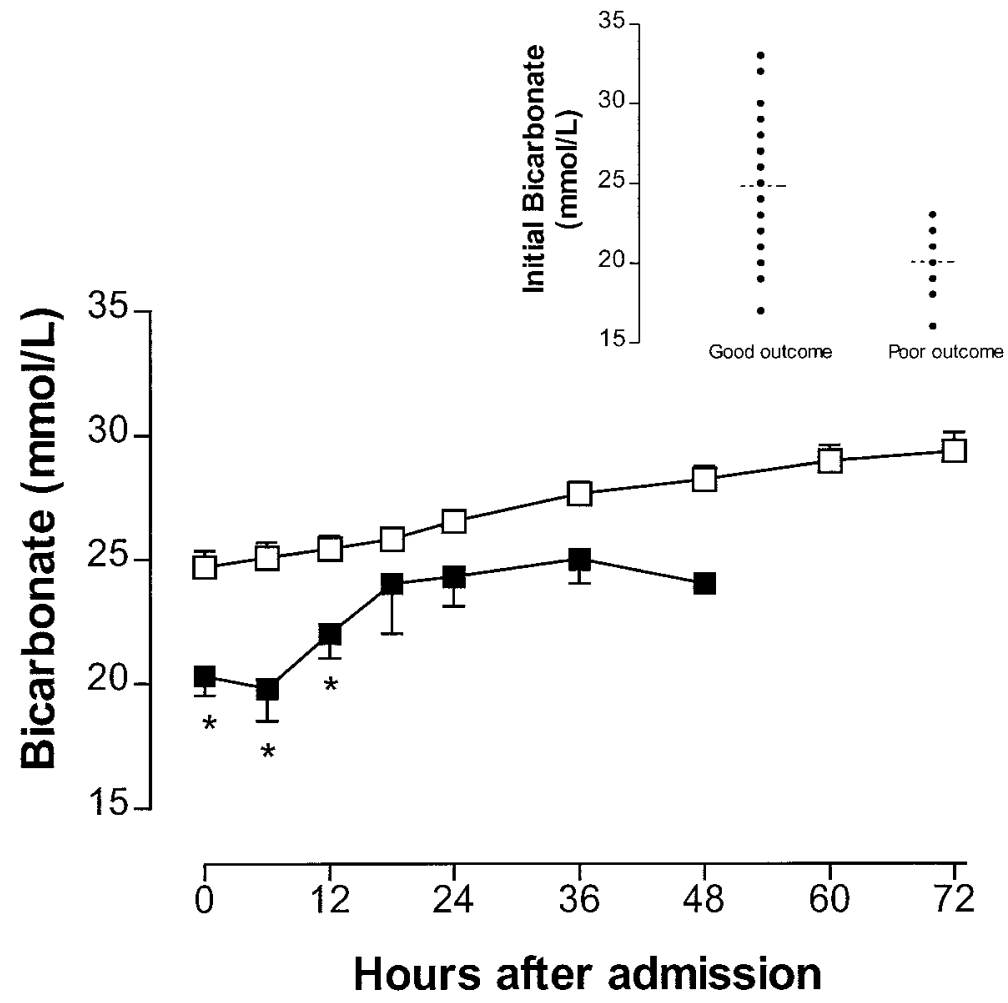

Fig 3. Serial bicarbonate levels for all patients during the first 72 hours after admission to the intensive care

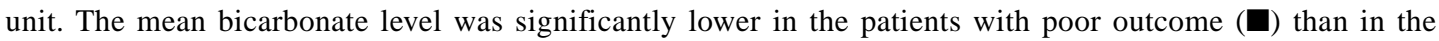
patients with good outcome $(\square)$ between 0 and 12 hours $(P<.05)$ but was not significantly different between 18 and 72 hours. The inset shows an overlap of individual initial bicarbonate levels between patients with good outcome $(25 \pm 3.8 \mathrm{mmol} / \mathrm{L})$ and patients with poor outcome $(20 \pm 2.3 \mathrm{mmol} / \mathrm{L})$, despite a significant difference $(P=.0003)$ on admission.

an adustment for both Norwood operation and change in lactate level over time) also did not demonstrate an association of cardiopulmonary bypass time or circulatory arrest time with outcome.

Group I. Thirty-four infants with a single ventricle after modified Norwood Stage I palliation ${ }^{13}$ were included in the study, and individual diagnoses and outcomes are listed in Tables I and II. Four patients died in the first 72 hours after operation (11.8\%), and 4 patients $(11.8 \%)$ required ECMO support.

Initial blood lactate concentration was significantly greater in patients who died or required ECMO support $(8.3 \pm 2.2 \mathrm{mmol} / \mathrm{L})$ than in patients who survived the Norwood procedure $(6.1 \pm 2.1 \mathrm{mmol} / \mathrm{L} ; P=.01)$, but there was considerable overlap in individual initial blood lactate levels between the good outcome and poor outcome groups (only a $35 \%$ positive predictive value for poor outcome for a lactate level of more than $6 \mathrm{mmol} / \mathrm{L})$. However, an increase in blood lactate level of $0.75 \mathrm{mmol} / \mathrm{L}$ per hour or more was strongly associ- ated with a poor outcome $(P<.0001$; Fig 5$)$, and predicted death or the requirement for ECMO support with an $88 \%$ sensitivity value, a $100 \%$ specificity value, and a $100 \%$ positive predictive value. The negative predictive value for a poor outcome of a lactate level rise of less than $0.75 \mathrm{mmol} / \mathrm{L}$ per hour was $96 \%$ $(P<.0001)$. As was the case when all patients were considered, serial mean lactate levels progressively declined in all patients in group I with a good outcome and were within the normal range by 24 hours.

For patients in group I, cardiopulmonary bypass time, but not circulatory arrest time, was longer in infants with a poor outcome $(86.6 \pm 20.9$ minutes $)$ than for infants with a good outcome $(69.9 \pm 18.7$ minutes; $P=.04)$. However, there was no significant association between lactate levels and cardiopulmonary bypass time or circulatory arrest time.

Group II. In addition to the patients who underwent Norwood palliation, 12 infants with complex congenital heart disease who underwent biventricular repair or 


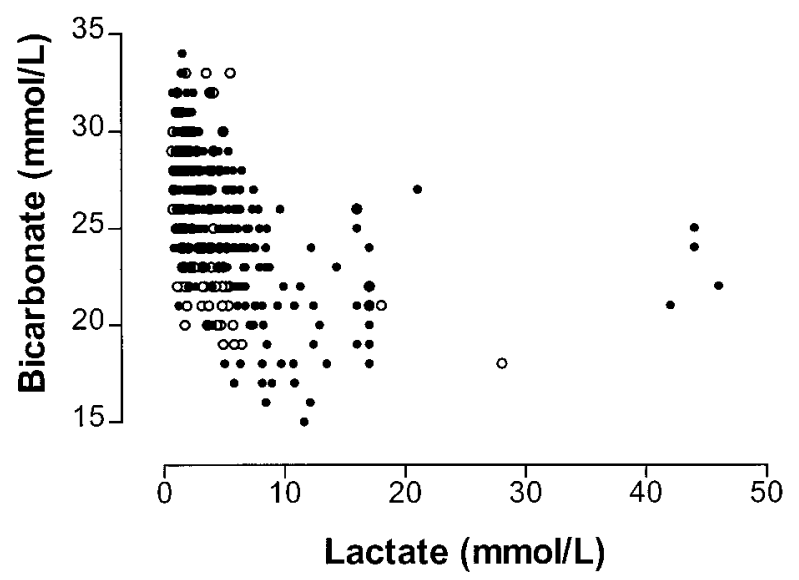

Fig 4. Individual arterial lactate concentrations were plotted against individual bicarbonate measurements at all times for both Norwood patients (group I; O) and non-Norwood patients (group II; $\bigcirc$ ). We found minimal correlation between the admission lactate levels and the bicarbonate measures $\left(R^{2}\right.$ $=0.21 ; P=.002)$.

palliation in the newborn period were enrolled in the study. The ranges of diagnoses and outcomes are listed in Tables I and II. One patient in group II died (8.3\%), and no patient required ECMO. The initial lactate level for the patient who died was $18 \mathrm{mmol} / \mathrm{L}$. In contrast, the mean initial lactate level for the 11 patients with a good outcome in group II was $4.2 \pm 1.5 \mathrm{mmol} / \mathrm{L}$, which was significantly lower than for patients in group I with a good outcome $(P=.005)$. However, similar to patients in group I with a good outcome, serial lactate levels fell progressively over the next 3 postoperative days to normal levels. Mean lactate level at 72 hours was $1.1 \pm 0.2 \mathrm{mmol} / \mathrm{L}(P=1.0$, compared with patients in group I with a good outcome at 72 hours).

For patients in group II, cardiopulmonary bypass time (136 \pm 45.6 minutes) and circulatory arrest time (34.7 \pm 20.5 minutes) were longer than for the one patient with a poor outcome (71 minutes and 26 minutes, respectively).

\section{Discussion}

Despite dramatic improvements in survival for infants with complex congenital heart disease, the mortality after neonatal repair or palliation remains significant. Most of these postoperative deaths occur early and have generally been attributed to low systemic output. It can be difficult to differentiate the patient in low output who is destined to have sudden cardiovascular collapse from a patient who will survive; a better means of making this determination

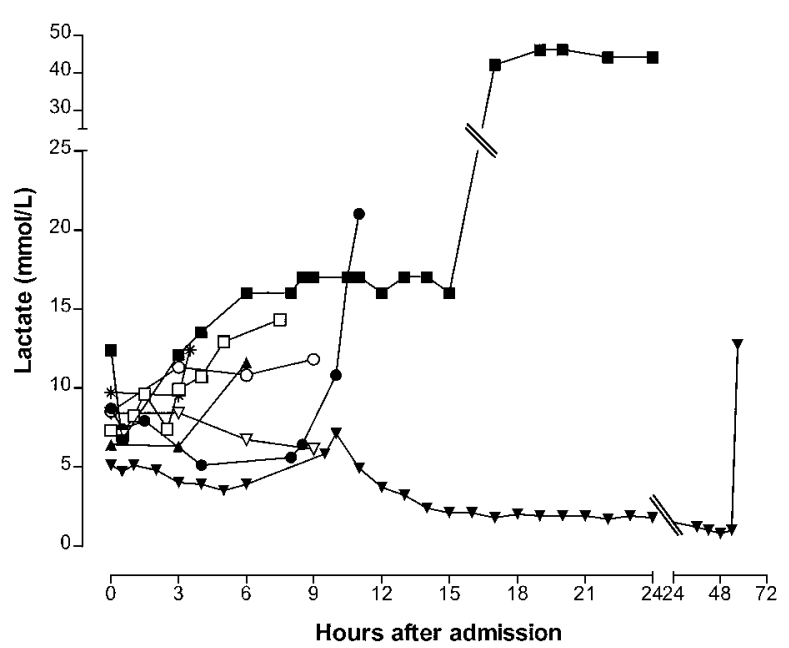

Fig 5. Serial lactate measurements taken during the first 72 hours after admission to the intensive care unit after Norwood palliation (group I) for each patient with a poor outcome. A significant increase in lactate level over time preceded death or the requirement for ECMO support in 7 of the 8 patients with a poor outcome $(88 \%$ sensitivity value, $100 \%$ specificity value, and $100 \%$ positive predictive value for a change of lactate level of $0.75 \mathrm{mmol} / \mathrm{L}$ per hour or more).

might allow for a modification of therapy in time to avert the collapse. Our data suggest that, for patients with a single ventricle after Norwood operation (group I), early postoperative death or the requirement for ECMO support was accurately predicted by an interval increase in serial blood lactate levels. The death of only 1 infant in the non-Norwood group (group II) precludes us from drawing any firm conclusions about the use of rising serial lactate levels in this population. However, a progressive decline in serial lactate levels seemed to be strongly associated with a good outcome in all patients.

Previous publications suggest that initial lactate levels are significantly related to poor outcome in children after cardiac operations. ${ }^{14-16}$ In one study, complicated outcomes (defined as death, open sternum, reoperation, cardiac catheterization, ECMO, and cardiac arrest) occurred in 32 of 109 consecutive patients after heart operations, and postoperative admission lactate levels for those patients with complicated outcomes were $8.6 \pm 6.1 \mathrm{mmol} / \mathrm{L}$ compared with $3.2 \pm 1.9$ $\mathrm{mmol} / \mathrm{L}$ in uncomplicated cases. ${ }^{14}$ Furthermore, lactate levels correlated with the degree of hypothermia while the patient was supported by cardiopulmonary bypass, the duration of cardioplegic arrest, the number of ventilator days, and the intensive care unit length of 
stay. ${ }^{14}$ In a second study, the initial mean lactate level after heart surgery in a pediatric population was 2.38 $\mathrm{mmol} / \mathrm{L}$ for survivors $(\mathrm{n}=34$ patients $)$ and 6.86 $\mathrm{mmol} / \mathrm{L}$ for nonsurvivors ( $\mathrm{n}=7$ patients); no patient with a blood lactate level of more than $4.5 \mathrm{mmol} / \mathrm{L}$ survived. ${ }^{15}$ More recently, Duke and colleagues ${ }^{16}$ found that blood lactate level, mean arterial pressure, and duration of cardiopulmonary bypass were the only significant, independent predictors of major adverse events when measured at the time of admission to the intensive care unit. The odds ratio for major adverse events, if an admission lactate level was greater than $4.5 \mathrm{mmol} / \mathrm{L}$, was 5.1. For blood lactate levels greater than $4 \mathrm{mmol} / \mathrm{L}$, this odds ratio increased to 8.3 at 4 hours and 9.3 at 8 hours. ${ }^{16}$

In contrast to these reports, Hatherhill and colleagues ${ }^{11}$ demonstrated a significant overlap in the initial lactate values between survivors and nonsurvivors after operation for complex congenital heart disease in children. Initial postoperative serum lactate levels of more than $6 \mathrm{mmol} / \mathrm{L}$ predicted death with a sensitivity value of $78 \%$, a specificity value of $83 \%$, and a positive predictive value of only $32 \%$. Therefore, these authors concluded that initial lactate concentrations have poor positive predictive value for death and that their routine measurement could not be justified. ${ }^{11}$

Recently, however, the determination of serial lactate levels has proved useful to increase both sensitivity and specificity of the test. In septic shock, both initial and serial measurements of lactate levels predict outcome and subsequent multiple organ failure, ${ }^{17}$ but sequential determinations of lactate levels yield a more reliable prognostic index than any single value alone. ${ }^{17,18}$ Our results confirm the findings of Hatherhill and colleagues ${ }^{11}$ that admission lactate levels are a poor predictor of early death or the requirement for ECMO support because of significant overlap between survivors and the patients who do not survive or who undergo ECMO. However, similar to the published data on septic shock, serial measurements of lactate levels yielded a more reliable prognostic index than a single lactate level and improved the sensitivity and specificity values of the test in infants with congenital heart disease who undergo repair or palliation.

An additional observation from our study is that only a weak correlation exists between lactate levels and calculated bicarbonate levels in patients with congenital heart disease after surgery. This minimal association between circulating lactate concentrations and acidbase status also has been reported by other investigators. ${ }^{19-22}$ In conditions of tissue hypoperfusion and acidemia, the source of excess hydrogen ions is the hydrolysis of adenosine triphosphate. ${ }^{23}$ Excess hydrogen ions are buffered, in part, by bicarbonate but also by other forms of therapy, including mechanical ventilation. Furthermore, acidemia promotes lactate uptake in tissues by the action of a $\mathrm{pH}$-sensitive lactate carrier. ${ }^{24}$ Thus, acidemia may influence circulating lactate concentrations independent of bicarbonate. Finally, unmeasured anions not related to lactate metabolism may contribute to metabolic acidosis..$^{25,26}$

In summary, these data suggest that serial blood lactate measurements may be an accurate predictor of death or the requirement for ECMO support for patients undergoing complex neonatal cardiac surgery and may be a useful adjunct to current practice in pediatric cardiac intensive care. We do not know whether this information can be generalized beyond high-risk patients, but even if limited to the Norwood population, the findings remain significant and possibly clinically useful. In the future, we speculate that serial lactate measurements may allow for timely modifications in therapy that may effectively reverse low systemic output and ultimately lead to an improved overall early survival after neonatal repair or palliation for complex congenital heart disease.

\section{REFERENCES}

1. Weil MH, Afifi AA. Experimental and clinical studies on lactate and pyruvate as indicators of the severity of acute circulatory failure (shock). Circulation 1970;41:989-1001.

2. Rashkin MC, Bosken C, Bauughman RP. Oxygen delivery in critically ill patients: relationship to blood lactate and survival. Chest 1985;87:580-4.

3. Cady LD Jr, Weil MG, Afifi AA, Michaels SF, Liu VY, Shubin H. Quantitation of severity of critical illness with special reference to blood lactate. Crit Care Med 1973;1:75-80.

4. Broder G, Weil MH. Excess lactate: an index of reversibility of shock in human patients. Science 1964;143:1457-9.

5. Kruse JA, Zaidi SAJ, Carlson RW. Significance of blood lactate levels in critically ill patients with liver disease. Am J Med 1987;83:77-82.

6. Peretz DI, Scott HM, Duff J, Dossetor JB, McLean LD, McGregor M. The significance of the lactic acidemia in the shock syndrome. Ann NY Acad Sci 1965;119:1133-41.

7. Fitzgerald MJ, Goto M, Myers TF, Zeller WP. Early metabolic effects of sepsis in the preterm infant: lactic acidosis and increased glucose requirement. J Pediatr 1992;121:951-5.

8. Beca JP, Scopes JW. Serial determinations of blood lactate in respiratory distress syndrome. Arch Dis Child 1972;47:550-7.

9. Graven SN, Criscuolo D, Holcomb TM. Blood lactate in the respiratory distress syndrome. Am J Dis Child 1965;110:614-7.

10. Cheung P-Y, Finer NN. Plasma lactate concentration as a predictor of death in neonates with severe hypoxemia requiring extracorporeal membrane oxygenation. J Pediatr 1993;125:763-8. 
11. Hatherill M, Sajjanhar T, Tibby SM, Champion MP, Anderson D, Marsh MJ, et al. Serum lactate as a predictor of mortality after pediatric cardiac surgery. Arch Dis Child 1997;77:235-8.

12. Deshpande SA, Ward Platt MP. Association between blood lactate and acid-base status and mortality in ventilated babies. Arch Dis Child 1997;76:15F-20F.

13. Bove EL, Lloyd TR. Staged reconstruction for hypoplastic left heart syndrome: contemporary results. Ann Surg 1996;224:387-94.

14. Shemie S. Serum lactate predicts post-operative complications after pediatric cardiac surgery. Pediatr Res 1996;39:54A:307.

15. Siegel LB, Dalton HJ, Hertzog JH, Hopkins RA, Hannan RL, Hauser GJ. Initial post-operative serum lactate levels predict survival in children after open heart surgery. Intensive Care Med 1996;22:1418-23.

16. Duke T, Butt W, South M, Karl TR. Early markers of major adverse events in children after cardiac operations. J Thorac Cardiovasc Surg 1997;114:1042-52.

17. Bakker J, Gris P, Coffernils M, Kahn RJ, Vincent J-L. Serial blood lactate levels can predict the development of multiple organ failure following septic shock. Am J Surg 1996;171:221-6.

18. Vincent J-L, Dufaye P, Berre J, Leeman M, Degaute J-P, Kahn RJ. Serial lactate determinations during circulatory shock. Crit Care Med 1983;11:449-51.
19. Aduen J, Bernstein WK, Miller J, Kerzner R, Bhatiani A, Davison L, et al. Relationship between blood lactate concentrations and ionized calcium, glucose, and acid-base status in critically ill and noncritically ill patients. Crit Care Med 1995;23:246-52.

20. Cooper DJ, Walley KR, Dodek PM, et al. Plasma ionized calcium and blood lactate concentrations are inversely associated in human lactic acidosis. Int Care Med 1992;18:286-9.

21. Nimmo GR, Grant IS, Mackenzie SJ. Lactate and acid base changes in the critically ill. Postgrad Med J 1991;67(suppl):S56-61.

22. Groeneveld AB, Kester AD, Nauta JJ, Thijs LG. Relation of arterial blood lactate to oxygen delivery and hemodynamic variables in human shock states. Circ Shock 1987;22:35-53.

23. Mizock BA. Controversies in lactic acidosis: implications in critically ill patients. JAMA 1987;258:497-501.

24. Gutierrez G, Hurtado FJ, Gutierrez M, Fernandez E. Net uptake of lactate by rabbit hindlimb during hypoxia. Am Rev Respir Dis 1993;148:1204-9.

25. Rackow E, Mecher C, Astiz ME, Goldstein C, McKee D, Weil $\mathrm{MH}$. Unmeasured anion during severe sepsis with metabolic acidosis. Circ Shock 1990;30:107-15.

26. Mecher C, Rackow EC, Astiz ME, Weil MH. Unaccounted for anion in metabolic acidosis during sepsis in humans. Crit Care Med 1991;19:705-11.

\section{Availability of Journal back issues}

As a service to our subscribers, copies of back issues of The Journal of Thoracic and Cardiovascular Surgery for the preceding 5 years are maintained and are available for purchase from Mosby until inventory is depleted. The following quantity discounts are available: $25 \%$ off on quantities of 12 to 23, and one third off on quantities of 24 or more. Please write to Mosby, Subscription Customer Service, 6277 Sea Harbor Dr, Orlando, FL 32877, or call 800-654-2452 or 407-345-4000 for information on availability of particular issues and prices. If unavailable from the publisher, photocopies of complete issues may be purchased from Bell \& Howell Information and Learning, 300 N Zeeb Rd, Ann Arbor, MI 48106-1346; 734-761-4700 or 800-521-0600. 